\title{
Budgeting System in Construction Organizations in Conditions of Process-Oriented Normative Model of Cost Accounting
}

Tukhvatullin R.S.

Kazan Federal University, Institute of Management, Economics and Finance, Kazan, 420008, Russia

Pratchenko O.V.

Kazan Federal University, Institute of Language, 420008, Kazan, Russia

Doi:10.5901/mjss.2014.v5n24p56

Abstract

The article analyses the features of the structure of the budgeting system in conditions of the process-oriented normative method of cost management. The authors set out the peculiarities of budget development in the construction industry, consider the stages of implementation of process-oriented budgeting in conditions of application the process-oriented normative method of cost management in construction industry. Using this model can be very useful for construction industry companies and help them set their goals to achieve performance indicators.

Keywords: budgeting, ABB-budgeting, ABC-costing, process, construction

\section{Introduction}

In conditions of the unstable economic situation the demand for cash flow planning, budgeting and financial analysis of performance increases in almost all construction companies. As a result, the budgeting system becomes relevant, it takes into account not only the industry-specific characteristics of the construction industry, but the requirements of an integrated accounting system as well.

Construction of the budgeting system should be done in close interconnection with the process-oriented normative model of cost management. The process-oriented normative model of cost management is an adaptation of two methods of cost accounting: regulatory accounting and accounting by functions (ABC-costing) [1, 2]. In conditions of application of the process-oriented normative model of cost accounting it is necessary to use costs calculations of construction works with details on key technological and service processes, and to analyze the cost items within these processes for the construction of budgets.

At that technological processes are processes that are directly connected with construction of the object (earthworks, piling work, roofing, etc.) [3]. In general, direct costs of construction industry are formed in the framework of these processes. Service processes are the processes aimed at maintaining the technological processes (determination of the construction work, making a construction contract, providing the construction site by resources, etc.). In the context of these processes overhead costs of construction industry are formed [4].

\section{Theory}

Due to the peculiarities of the construction industry, the budgeting process is somewhat different from the methodology in other industries $[5,6]$. For example, the following factors are analyzed in production and trade: market capacity, shipments, customer behavior, etc. Then, based on the analysis of these indicators, the trading budget is formed; it is followed by the production budgets, selling costs, wages, etc.

In our opinion, in the construction industry the sales budget should not be drawn up, the construction budget fulfills its functions. Construction cycle does not depend on the plan of sales, and the construction of the budgeting process in the construction industry on the basis of the sales budget is impossible.

In the classical variant the design estimation documentation is always in the basis of the construction budget [7]. The authors do not deny this statement, but at the same time, we believe that the process-oriented approach for drawing up of budgets should be in the basis of drawing up of the construction budget, which, in its turn, requires data correction 
of design and estimation documentation.

The fact that the planning should be carried out not only by budget items, but linked to a specific project as well (as far as each investment-construction project has a clear construction schedule, cost estimates, which cannot be broken), as well as in the context of technological and service processes of construction organization, is the feature of the budgets of construction companies. At the same time technological processes are divided on the basis of design and estimation documentation, and service processes - according to the process-oriented methodology (ABB budgeting). In conditions of application of ABB-budgeting the budgets are developed on the basis of activities (functions performed) of construction organizations.

\section{Results}

The authors developed the methodology of introduction of the process-oriented budgeting in conditions of application the process-oriented normative method of cost management [8].

\subsection{Determination of quantitative requirements in the basic processes}

The presence of this stage does not cancel the obligation of priority of construction budgeting, on the basis of which the indicators of the other budgets are formed in the traditional system of budgeting. When applying the ABB-method, the estimated budget of construction in natural and value is only one of the drivers which is necessary for making the budgeting operations [9]. On the basis of design and estimation documentation for construction the calculation of the required level of intensity of the main production processes (basic operations) is made in order to produce the required amount of production.

At the first stage it is necessary to form the production program which will take into account the peculiarities of the cost-oriented budgeting. It is necessary to correlate the formation of the production program with drawing up of construction documentation on the basis of previously signed construction contracts. At that the technological processes will be presented by the direct costs in cost estimating documentation, and servicing ones - by overhead costs. Due to the nature of pricing in the construction industry and the methodology of determination of the estimated cost of construction the enlarged value of the overhead costs should be presented as a set of service processes allocated on the basis of $A B C$-costing methodology.

In conditions of application of the cost-oriented budgeting the production program presents only generalized indicators. As a result, it is necessary to detail the processes by names of processes, by articles, as well as by their elements.

In conditions of construction of the process-oriented budgeting the formation of the work schedule with possibility to create any hierarchy (phases, groups, subgroups) for more construction projects, as well as for drawing up the tables for the analysis of the performance plan of construction work is of great importance.

In our opinion, such presentation of information in conditions of application of the process-oriented normative method of cost accounting and its automation, will allow for the management of the analyzed building organization:

- $\quad$ to form schedules with possibility to create any hierarchy (of processes, phases, groups, subgroups, etc.);

- to control the appointment of the responsible executives for the performance of works of the schedule of labor and technical resources;

- to make up the schedules of resources in the context of work, as well as the schedules of use of materials in the context of works;

- aim and reflection of logical relationships between the works with possibility of delay in time and size;

- to keep a record of the real performance of work according to the schedule;

- to form reports of the use of resources on selected construction sites, in the context of works of any frequency, etc.

At the output of the first stage, we obtain the information concerning quantitative demand in intensity of technological and service operations in order to achieve the planned volume of construction works.

\subsection{Determination of need for direct costs}

In construction companies this stage of is not difficult, since the calculation of direct costs is carried out according to the norms of consumption of raw materials per unit of production, regulatory labor intensity, etc. In other words, the standard norms of consumption of fixed costs per cost unit are used [6]. 
At this stage, on the basis of design and estimation documentation the information for the number of sub-budgets linked to specific technological processes is detailed. For example, the operation "pasting of roll materials on asphalt mastic" refers only to the technological process - "Installation of four-flat roofs, from roll roofing materials", while it is not reflected in the other processes.

Formation of needs in technological processes should be in connection with creation of construction schedules and have the information for further use of the basis of the process-normative method of cost accounting. In our opinion, creating the need for industrial processes should be in two stages [10]:

- formation of the local resource cost budget in context of technological process;

- formation of the final local cost budget with relevant standards and the estimated cost budget of the process.

\subsection{Determining of need for servicing operations}

This stage is the most complicated in the process -oriented budgeting. The fact is that in the construction industry the serving (management) processes are calculated as a percentage of the value of the wage fund, and it is an abstract amount.

At the same time, as it has already been mentioned, the process-oriented approach is aimed to reflect the causeand-effect relationships of costs in the construction company with more details. In the process of determination of need for service processes it is necessary to use the planning values of costs in the context of the allocated functions (processes). For example, among serving processes it is possible to say about the following ones functions: preparation and control of the production process, provision of building sites by resources for production, storage of construction materials, preparation of orders for support production, technical control of construction, etc. In our opinion, in the process of determination of need for service processes it is necessary to use the planning values in the context of the allocated functions (processes).

\section{4 Определение потребности в ресурсах}

At drawing up the budgets in the construction industry the technology of creation for the resource needs can be as follows:

- lists of cost items included in the cost of every technological and service process are preliminarily determined;

- the drivers for serving processes are determined (the parameter, proportionally to which the costs are transferred to the cost of resources) for each line item;

- standards for flow-rate of drivers of dependent costs in the context of serving processes per unit of driver operation are determined;

- the norm of flow-rate of the driver of the cost budget is multiplied by the budgetary value of the driver operation, and finally we get there is a natural (sometimes even value) expression of the budget line. Then the natural expression of the budget line is multiplied by the expected rate of cost driver (number of processed documents, time of work, number of inspections of technical supervision, etc.), and the ruble value of these costs is found as a result of these calculations;

- For the formation of further analysis of costs in the construction industry it is also necessary to determine the overrun or under-utilization of cost drivers, as well as to interconnect with other operations in order to reduce its overrun or under-utilization.

According to the results of charges the data concerning underutilized time of workers is brought to a single database, analyzed, and managerial decisions are made on its basis. As a result of these decisions the risk of implicit losses should decrease at the expense of internal resources, and accordingly the high performance efficiency of the organization will be reached [11].

The amount of costs of serving processes which depend on the operations cost drivers of cost items are set for the whole organization, or by departments, and then they are distributed to organizations in proportion to the cost drivers.

The titles of cost drivers can remain unchanged for a long period of time. At the same time, at this stage it is much more important to determine the values of the budget cost drivers, most of which are described as "external", i.e. formed in the process of consumption of resources belonging to other organizations. In most cases the determination of quantities of cost carriers cost is possible by the study of their dynamics over the past periods. 


\subsection{Calculation of costs for maintenance of the desired amount of resources.}

At this stage of the calculation of the final budget cost of every operation is carried out: technological processes - on the basis of the design and estimation documentation, and service processes - by adding the preliminary value of all cost items included in them. Due to the fact that these budget cost values (especially service processes) are only preliminary, it can lead to deviations, which are caused by changes in rates of drivers operations.

The authors offer to make the calculation of the final cost of operations, as well as the rates of cost drivers in specially designed analytical tables, which in process- oriented budgeting can be also called the budget of operations and the budget of resources. [10]

In accordance with the methodology of the process-oriented budgeting the operations budget (in terms of technological processes) is based on the construction budget which contains information about planned construction projects. Then, on the basis of the budget of operations (technological processes) the remaining part of the budget of operations (service processes) and the budget of resources are formed. The data of the budget of resources are used to calculate the planned overhead costs by three budgets: the budget of general production costs, the budget of commercial budgets and the budget of general running (overhead) costs.

All the other budgets of the system of process-oriented cost budgeting do not differ from traditional budgets in form.

\subsection{Budgeting procedure by the methodology of ABB-budgeting}

As it has already been mentioned, the change in methodology of calculation of the target values of costs requires changing the form of budgets. Change of the approach for budgeting influences the planning costs from operating activities, so it does not bring any significant changes in the structure of indicators and methods of calculation of financial budgets. All changes take place on the operational level, where there is the budgeting of costs.

Making up of the generalized budget of costs of construction projects is the main objective of this stage. Budget of costs should consist of two sections, the first section is made to reflect the distribution of service processes for technological processes. At that the cyclic dependencies can occur among serving processes. As a result, with respect to these processes the step-by-step method of cost allocation can be supplemented by techniques of the relative distribution. It is also important to say that a lot of service processes in the construction industry can be directly attributed to technological processes. These processes can be grouped in a separate form of the first section or attached as separate lines called "directly attributable to technological processes."

The second section of the budget is intended to reflect the process of calculation of costs of construction work. The distributed amount of service processes - with the account of redistributed mutual services (if necessary) of the budget processes - is added to the budget value of technological processes (direct costs) for the relevant positions of objects of calculation.

\subsection{Analysis of the Identified Deviations within the Application of the Process}

At the end of the reporting period, the data of budgets should be analyzed. For this preliminary and actual costs of performance, as well as the rates of processes drivers are compared in special registers. We recommend to find the total deviation for each process, focusing on which in future it will be possible to make deeper analysis of the cost of operations in the context of its items revealing reserves for cutting the rates.

The degree of impact of the rate on the cost of the operation performance depends entirely on the value of the driver operation. In some cases, even small changes in rates can lead to significant cost overruns due to the large values of the driver operation. At the same time a relatively small deviation of the driver - even with a high rate - makes it possible to postpone such operation [2].

\section{Conclusion}

In conditions of the process-oriented cost budgeting the formation of budgetary performance indicators in the construction industry makes calculations more complicated. At the same time, the information generated in the system of the ABBmethod is more accurate and detailed, and it can be used for the analysis of the expected load of building sites and construction machines and mechanisms, for the study and adjustment of the cost value of operations, for calculation of the well-founded cost of construction works and financial results, etc. 


\section{References}

Adamov N.A. Accounting, analysis and audit in construction. Tutorial. Finance and Statistics. 2006. p.320.

Bagaev I.V. Formation of budgetary indicators of trading organization in the conditions of ABB-method application. Management accounts, 2008; 2: 4-13.

Beketov N.V., Denisova A.S. Budgetary planning in the companies. Economic analysis: theory and practice, 2008; 5:14-17.

Brimson J. Process cost budgeting. The introduction of a new management tool of the valuation company. M.: Varshina, 2007.

Brimson J. Driving value using activity-based costing. M.: Varshina, 2007.

Boiko D.V. Budgeting governance in construction's companies. Audit Statements, 2008; 3: 59-65.

Garifullin K.M. Cost management. Kazan State Finance and Economics Institute. Kazan. 2005. p. 316.

Tukhvatullin R.Sh., 2009. Poprocessno-normative method of accounting and analysis of costs in the building production. D.S. thesis, Kazan State Finance and Economics Institute, Kazan, Russia.

Kazakov A., Kazancev K. Automation of budgeting for building holdings. Business management, 2004; 11: 26-28.

Tukhvatullin R.Sh. Construction of system of budgeting for formation of the analytical information in the conditions of application of process-standard model of the account of expenses in building. Economic analysis: theory and practice, 2010; 4(169): 52-59.

Safiullin M.R., Elshin L.A., Shakirova A.I., Ermolaeva P.O., Prygunova M.I. (2013). Influence of Territorial Ecological Load Factors on Social and Economic Well-Being of Population: Methodology Development and Econometric Model Construction. World Applied Sciences Journal 25, 7, 1057-1061.

Kulikova L.I. Professional judgment accountant for accounting for construction contracts. Accounting, 2010; 5: 36-41. 